\title{
Effect of Early Enteral Feeding on A polipoprotein Al Levels and High-Density Lipoprotein Heterogeneity in Preterm Infants
}

\author{
Orsolya Genzel-Boroviczény ${ }^{a}$ Yvonne Göbel ${ }^{b}$ Berthold Koletzkob \\ aDepartment of Neonatology, Klinikum Grosshadern, and bivision of Metabolic Disorders, Molecular Disorders, \\ and Nutrition, Kinderklinik and Kinderpoliklinik, Ludwig Maximilians University, Munich, Germany
}

\section{Key Words}

Neonates, parenteral nutrition $\cdot$ High-density lipoprotein heterogeneity, premature infants · Apo Al levels

\begin{abstract}
Background/Aim: We have previously shown that infants receiving total parenteral nutrition have low apolipoprotein Al levels which are associated with high-density lipoprotein (HDL) class distributions as in lecithin:cholesterol acyltransferase deficiency. This study investigates the influence of early enteral feedings on apolipoprotein Al and HDL subclasses. Methods: Apolipoprotein Al and HDL distributions were determined in 15 total parenterally fed preterm infants (TPN group) receiving early feedings, in 28 enterally fed preterm infants (ENT group), and in 26 term infants at birth and on day 5. The HDL subclasses were determined by gradient gel electrophoresis. Results: In the TPN group, the apolipoprotein Al levels increased significantly postnatally (from $73 \pm 16$ to $104 \pm 23 \mathrm{mg} / \mathrm{dl}$ ) to levels found in the term and ENT groups on day 5 ( $88 \pm 16$ and $96 \pm 19 \mathrm{mg} / \mathrm{dl}$ ). The HDL subclass distributions at birth and on day 5 were similar in both TPN and ENT groups with more large $\mathrm{HDL}_{2 b}$ and less small $\mathrm{HDL}_{3 c}$ than in term infants. Whereas the $\mathrm{HDL}$ subclass distribution of term infants remained unchanged, in TPN and ENT infants, a shift from $\mathrm{HDL}_{2 b}$ to $\mathrm{HDL}_{3 c}$ was observed, with no difference between term
\end{abstract}

and preterm infants on day 5 . Conclusion: In contrast to exclusively parenterally fed infants, infants receiving early enteral feedings exhibited a significant rise of apolipoprotein $\mathrm{Al}$ and $\mathrm{HDL}$ subclass distributions as fully enterally fed preterm infants.

Copyright (C2002 S. Karger AG, Basel

\section{Introduction}

The benefits of early enteral nutrition in parenterally fed preterm infants have received increased attention. The levels of gut hormones and regulatory peptides, such as motilin, neurotensin, enteroglucagon, gastrins, and gastric inhibitory peptide, increase, when preterm infants are started on enteral feedings soon after birth, as opposed to very low levels seen in infants that are not yet fed $[1,2]$. Minimal enteral feedings also improve the maturation of the intestinal motility [3-5]. Nevertheless, parenteral nutrition with glucose, amino acids, and intravenous fat emulsion is essential to meet the substrate needs of sick preterm infants during the first weeks of life.

High-density lipoproteins (HDL) represent a heterogeneous population of particles based on both density and size. Two major ultracentrifugal density classes are recognized within the HDL spectrum: the less dense $\mathrm{HDL}_{2}$ and the more dense $\mathrm{HDL}_{3}$. The HDL heterogeneity has been redefined on the basis of particle size using nondenaturing

\begin{tabular}{ll}
\hline KARGER & ( 2002 S. Karger AG, Basel \\
0250-6807/02/0464-0121\$18.50/0 \\
$\begin{array}{l}\text { Fax +41613061234 } \\
\begin{array}{l}\text { E-Mail karger@karger.ch } \\
\text { www.karger.com }\end{array}\end{array}$ & $\begin{array}{l}\text { Accessible online at: } \\
\text { www.karger.com/journals/anm }\end{array}$
\end{tabular}

Orsolya Genzel-Boroviczény, MD, Department for Neonatology
Klinikum Grosshadern, Ludwig Maximilians University
Marchioninistrasse 15, D-81377 Munich (Germany)
Tel. +49 897095 2808, Fax +49 8970952809

E-Mail genzel@helios.med.uni-muenchen.de 
gradient gel electrophoresis $[6,7]$. There are at least five distinct HDL subpopulations within the normal adult density region. In the $\mathrm{HDL}_{3}$ fraction (density 1.125-1.20 $\mathrm{g} / \mathrm{ml})$, three subpopulations are found: $\mathrm{HDL}_{3 \mathrm{a}}(8.8-8.2$ $\mathrm{nm}), \mathrm{HDL}_{3 \mathrm{~b}}(8.2-7.8 \mathrm{~nm})$, and $\mathrm{HDL}_{3 \mathrm{c}}(7.8-7.2 \mathrm{~nm})$. The $\mathrm{HDL}_{2}$ fraction (density $1.063-1.125 \mathrm{~g} / \mathrm{ml}$ ) contains the following two subpopulations: $\mathrm{HDL}_{2 \mathrm{~b}}(12.9-9.7 \mathrm{~nm})$ and $\mathrm{HDL}_{2 \mathrm{a}}(9.7-8.8 \mathrm{~nm})$. In adults, $\mathrm{HDL}_{3 \mathrm{a}}$ is the predominant HDL subspecies, while in cord blood this is a minor subspecies $[8,9]$. The increase in cholesterol as observed in the cord blood samples of preterm infants consists mainly of HDL cholesterol and is associated with an increase of particles in the $\mathrm{HDL}_{2 b}$ region [8]. We have previously shown $[10,11]$ that within the first days of life fasting preterm neonates have low HDL cholesterol and apolipoprotein (apo) AI levels and low HDL subclass distributions, not unlike lecithin:cholesterol acyltransferase (LCAT) deficient patients. Intravenous parenteral nutrition with lipid emulsions is associated with increases in apo AI and LCAT concentrations and changes in HDL subclass distribution. The apo AI level is low prior to parenteral nutrition, in particular in a subgroup of infants with enteral problems like necrotizing enterocolitis, and increases with parenteral nutrition, but only reaches normal levels after the introduction of enteral nutrition. Two adult patients maintained on total parenteral nutrition after total small-bowel resection had apo AI and HDL cholesterol levels $70-50 \%$ of normal. Alterations of the amounts of infused phospholipid influenced cholesterol, phospholipid, and apo B plasma levels, but not apo AI and HDL cholesterol levels. The small intestine is important as source of apo AI and for HDL cholesterol metabolism [12], since significant amounts of apo AI are secreted by the intestine [13].

The influence of gut priming with small amounts of enteral feedings from the 1st day of life on apo AI levels and HDL subclass distribution has not been previously investigated in preterm infants receiving parenteral nutrition including lipid emulsions.

In the present report we evaluated HDL subpopulations and apo AI levels in parenterally fed preterm infants with early enteral feedings in comparison to fully enterally fed preterm and term infants.

\section{Patients and Methods}

\section{Patients}

Preterm infants with a gestational age $\leq 32$ weeks (as defined by ultrasound examinations early in gestation) were enrolled after parental consent (total parenteral nutrition; TPN group). The infants received parenteral and early enteral nutrition by the standard protocol of the intensive care nursery: TPN with glucose, amino acids, and calcium gluconate was started immediately after admission and supplemented with parenteral fat emulsion $\left(20 \%\right.$, Intralipid ${ }^{\circledR}$; Pharmacia) and parenteral multivitamin solution on days $2-3$ of life. Parenteral fat emulsion ( $20 \%$ soybean oil, $1.2 \%$ egg yolk phospholipid, and $2.2 \%$ glycerol) was started at $0.5 \mathrm{~g} / \mathrm{kg} /$ day and advanced by $0.5 \mathrm{~g} /$ $\mathrm{kg} /$ day to a maximum of $3 \mathrm{~g} / \mathrm{kg} /$ day if tolerated. Fat was administered intravenously continuously over $24 \mathrm{~h}$. The infants received $1-$ $3 \mathrm{ml}$ of diluted preterm formula every $3 \mathrm{~h}$, starting on the 1 st day of life, as gavage feeding, and feedings were advanced daily as tolerated. Parenteral and enteral nutrition was advanced by clinical status and by discretion of the attending neonatologist. All infants received pumped breast milk as soon as available. Cord blood was obtained as baseline sample. Further blood samples were drawn on days 2 and 5 of life at times of routine blood sampling from indwelling catheters or by venipuncture. Preterm infants with gestational ages $>32$ weeks who tolerated enteral feedings and did not require parenteral nutrition were also recruited (enteral nutrition; ENT group), and cord blood and further blood samples were obtained on days 2 and 5 at times of routine blood sampling just prior to their next feeding. The preterm infants were gavage- or bottle-fed every $3 \mathrm{~h}$, but were started on breast-feeding as soon as possible. To prevent hypoglycemia, preterm infants with a birth weight $<2,000 \mathrm{~g}$ routinely received glucose solutions intravenously on days 1 and 2 . If parenteral lipid emulsion was given, the infant was excluded. Healthy term infants represented the third group (TERM group). In addition to cord blood, blood samples were obtained on day 5 at the time of the mandatory newborn screening for inborn metabolic and endocrine diseases and on day 2 if clinically indicated. The majority of the TERM group infants were breast-fed on demand. The study underwent review by the Ethics Committee of the Medical Faculty of the Ludwig Maximilians University, Munich.

\section{Lipid Concentrations}

Plasma was stored at $-80^{\circ} \mathrm{C}$ before analysis. Plasma triglyceride (TG) and total cholesterol (TC) levels were determined on a Kodak autoanalyzer by the glycerophosphate-oxidase/cholesterol-oxidaseperoxidase method (Kodak Vitros 250; Johnson \& Johnson, Braunschweig, Germany). HDL/HDL 3 cholesterol was determined by the HDL cholesterol polyethyleneglycol precipitation method with subsequent cholesterol analysis (Immuno, Heidelberg, Germany). Apo AI and apo AII concentrations were measured by single radial immundiffusion (Immuno). The phospholipid concentration was determined by using a glycerophosphate-oxidase/cholesterol-oxidase-peroxidase/phospholipase D-choline-oxidase phospholipid kit (Wako, Neuss, Germany).

\section{Lipoprotein Isolation and Nondenaturing Gradient Gel Electrophoresis}

To accommodate to the very small blood samples, the methods were modified so that only $100 \mu 1$ of plasma was necessary. The plasma was adjusted to a density of $1.21 \mathrm{~g} / \mathrm{ml}$ with a $\mathrm{NaBr}$ solution and preservation agents, as described by Schumaker and Puppione [14]. For analysis of the HDL subgroup distribution, the total lipoprotein fraction of the plasma was separated by ultracentrifugation. The density $\leq 1.21 \mathrm{~g} / \mathrm{ml}$ fraction was isolated in a single ultracentrifugation step utilizing only $100 \mu \mathrm{l}$ of plasma to which $130 \mu \mathrm{l}$ of a solution containing plasma conservation agents [14] and sodium bromide was added. Samples with added salt solution and preservatives were 
Table 1. Parenteral and enteral calories, protein, and fat of the 15 preterm infants (TPN group) receiving parenteral nutrition with lipid emulsion and minimal enteral feeding as gut priming from day 1 of life (mean $\pm \mathrm{SD}$ )

\begin{tabular}{|c|c|c|c|c|c|c|}
\hline & \multicolumn{3}{|l|}{ Intravenous } & \multicolumn{3}{|l|}{ Enteral } \\
\hline & $\begin{array}{l}\text { calories } \\
\mathrm{kcal} / \mathrm{kg} / \text { day }\end{array}$ & $\begin{array}{l}\text { protein } \\
\mathrm{g} / \mathrm{kg} / \text { day }\end{array}$ & $\begin{array}{l}\text { fat } \\
\mathrm{g} / \mathrm{kg} / \text { day }\end{array}$ & $\begin{array}{l}\text { calories } \\
\mathrm{kcal} / \mathrm{kg} / \text { day }\end{array}$ & $\begin{array}{l}\text { protein } \\
\mathrm{g} / \mathrm{kg} / \text { day }\end{array}$ & $\begin{array}{l}\text { fat } \\
\mathrm{g} / \mathrm{kg} / \text { day }\end{array}$ \\
\hline Day 2 & $24 \pm 6.9$ & $0.7 \pm 0.2$ & $0.4 \pm 0.2$ & $11 \pm 7.1$ & $0.3 \pm 0.2$ & $0.5 \pm 0.3$ \\
\hline Day 5 & $29 \pm 7.8$ & $0.8 \pm 0.3$ & $1.2 \pm 0.4$ & $50 \pm 17$ & $1.4 \pm 0.5$ & $2.6 \pm 0.5$ \\
\hline
\end{tabular}

stored in the ultracentrifugation test tubes at $-20^{\circ} \mathrm{C}$ until ultracentrifugation. Ultracentrifugation was carried out in an LP 42.2 Ti rotor and an L8-55 M ultracentrifuge (all from Beckman, Munich, Germany) at $42,000 \mathrm{rpm}$ and $20^{\circ} \mathrm{C}$ for $6 \mathrm{~h}$, and subsequently the $50-\mu 1$ top fraction containing the total lipoprotein fraction was harvested by tube cutting (CentriTube Slicer, Beckman). Frozen and stored samples were compared with refrigerated $\left(4^{\circ} \mathrm{C}\right)$ samples stored for $24 \mathrm{~h}$, and no difference with regard to HDL subclass distribution was found. Gradient gel electrophoresis was carried out on precast polyacrylamide gradient gels (4-30\%; David Rainwater, San Antonio, Calif., USA) according to the procedure of Nichols et al. [6]. The gels were stained with Coomassie brillant blue to identify protein peaks, and densitometric scans were obtained with a TLC Scanner II (Camag, Berlin, Germany). The reference proteins used to determine the particle diameter were thyroglobulin, apoferritin, catalase, lactate dehydrogenase, and bovine serum albumin. The area under the curve was calculated for the five HDL subclasses. Blanche et al. [7] found a good correlation between percent area of HDL subgroups and plasma concentrations obtained by analytical ultracentrifugation [7].

\section{Statistics}

Mean values for cord blood and for blood sampled on days 2 and 5 were compared using ANOVA for the three groups. Changes of the values from cord blood to day 5 were assessed using paired t tests of mean values of each group. For the analysis of the values for infants with three samples, ANOVA was employed. Adjustment for multiple comparisons was done by the appropriate post tests (Dunnett and Bonferroni). For all calculations, Graphpad Prism 2.01 for Windows 3.1 (GraphPad Software, San Diego, Calif., USA) was used. Statistical significance was assumed with $\mathrm{p}<0.05$

\section{Results}

Fifteen preterm TPN infants, 28 healthy preterm ENT infants, and 26 healthy TERM infants (birth weights and gestational ages: TPN 1,521 $\pm 304 \mathrm{~g}$ and $30 \pm 2$ weeks; ENT 2,253 $\pm 296 \mathrm{~g}$ and $34 \pm 1$ weeks; TERM 3,242 \pm $489 \mathrm{~g}$ and $39 \pm 1$ weeks, respectively) were included in the study after obtaining parental consent.

In table 1, parenteral and enteral caloric intakes for the TPN group are shown. Of the 28 infants of the ENT group, 13 were breast-fed very early on, and as in the healthy TERM group, the caloric intake could not be recorded reliably. The remaining 15 infants of the ENT group were either bottle- or gavage-fed, and the intake could be recorded. In comparison to the TPN group, their intravenous caloric intake was minimal on day 2 , and they were on full enteral feedings on day 5 .

\section{Lipid Levels}

The lipid and apo levels in cord blood and on day 5 of the three groups are shown in table 2. Since the lipid levels on day 2 were not available in all infants (TERM group $n=6$; ENT group $n=15$; TPN group $n=8$ ), they are not included in the table.

The TC and TG values increased significantly from cord blood values to day 5 in all three groups. On day 5 , the TG values of the TERM infants were significantly higher than those of both groups of preterm infants. Since the TERM infants were breast-fed on demand, not all samples were obtained $3 \mathrm{~h}$ after the last meal.

Both groups of preterm infants had significantly higher TC values not only at birth, but also on day 5 . The HDL cholesterol levels were also significantly higher at birth in both groups of preterm infants (ENT and TPN groups) in comparison to the TERM group, but decreased thereafter, so that on day 5 , there was no significant difference between the three groups. For all preterm infants there was no significant correlation between gestational age and any of the lipid levels or the apo AI and AII levels. The TERM infants did not show any significant changes in their HDL cholesterol concentration from cord blood to day 5. The apo AI and apo AII levels increased significantly in all three groups and did not differ at any time between the three groups. At birth, the phospholipid levels were higher in both groups of preterm infants as compared with the TERM group. The phospholipid levels increased postnatally in all three groups. For the preterm 
Table 2. Lipid (mmol/l) and apo AI and apo AII $(\mathrm{mg} / \mathrm{dl})$ values (mean $\pm \mathrm{SD})$ in cord blood and on day 5 for the three groups TERM $(n=26)$, ENT $(n=28)$, and TPN $(\mathrm{n}=15)$

\begin{tabular}{|c|c|c|c|c|}
\hline & Cord blood & Day 5 & Cord blood & Day 5 \\
\hline & \multicolumn{2}{|l|}{ TG } & \multicolumn{2}{|l|}{$\mathrm{TC}$} \\
\hline TERM & $0.46 \pm 0.22$ & $1.66 \pm 0.8^{*}$ & $1.40 \pm 0.4$ & $2.75 \pm 0.12 *$ \\
\hline ENT & $0.38 \pm 0.21$ & $1.14 \pm 0.4^{*, a}$ & $2.22 \pm 0.6^{\mathrm{a}}$ & $3.00 \pm 0.9 *, \mathrm{a}$ \\
\hline \multirow[t]{2}{*}{ TPN } & $0.37 \pm 0.14$ & $1.25 \pm 0.74 *, \mathrm{a}$ & $2.60 \pm 0.8^{\mathrm{a}}$ & $3.60 \pm 1.08^{*, \mathrm{a}}$ \\
\hline & \multicolumn{2}{|c|}{ HDL cholesterol } & \multicolumn{2}{|c|}{$\mathrm{HDL}_{3}$ cholesterol } \\
\hline TERM & $0.62 \pm 0.2$ & $0.70 \pm 0.2$ & $0.40 \pm 0.13$ & $0.45 \pm 0.13$ \\
\hline ENT & $1.08 \pm 0.3^{\mathrm{a}}$ & $0.80 \pm 0.25^{*}$ & $0.65 \pm 0.15^{\mathrm{a}}$ & $0.52 \pm 0.15^{*}$ \\
\hline \multirow[t]{2}{*}{ TPN } & $1.08 \pm 0.3^{\mathrm{a}}$ & $0.78 \pm 0.2^{*}$ & $0.72 \pm 0.2^{\mathrm{a}}$ & $0.55 \pm 0.15^{*}$ \\
\hline & \multicolumn{2}{|l|}{ apo AI } & \multicolumn{2}{|l|}{ apo AII } \\
\hline TERM & $70 \pm 16$ & $88 \pm 16^{*}$ & $23 \pm 6$ & $28 \pm 6^{*}$ \\
\hline ENT & $78 \pm 14$ & $96 \pm 19 *$ & $26 \pm 5$ & $31 \pm 6^{*}$ \\
\hline \multirow[t]{2}{*}{ TPN } & $73 \pm 16$ & $104 \pm 23^{*}$ & $23 \pm 8$ & $29 \pm 7 *$ \\
\hline & \multicolumn{2}{|c|}{ HDL cholesterol/apo AI } & \multicolumn{2}{|c|}{ phospholipids } \\
\hline TERM & $0.36 \pm 0.08$ & $0.32 \pm 0.07$ & $1.22 \pm 0.25$ & $2.35 \pm 0.47^{*}$ \\
\hline ENT & $0.51 \pm 0.17^{\mathrm{a}}$ & $0.33 \pm 0.05^{*}$ & $1.58 \pm 0.37^{\mathrm{a}}$ & $2.42 \pm 0.37 *$ \\
\hline TPN & $0.59 \pm 0.12^{\mathrm{a}}$ & $0.28 \pm 0.12 *$ & $1.70 \pm 0.37^{\mathrm{a}}$ & $2.73 \pm 0.21^{\mathrm{a}, \mathrm{b}, *}$ \\
\hline
\end{tabular}

* Cord blood vs. day 5 , a in comparison to TERM infants, ${ }^{b}$ in comparison to the ENT group $(\mathrm{p}<0.001)$.

Table 3. Area under the curve in percent of the gradient gel electrophoresis scans (mean \pm SD)

\begin{tabular}{|c|c|c|c|c|c|c|c|c|c|c|}
\hline & \multicolumn{2}{|l|}{$\mathrm{HDL}_{2 \mathrm{~b}}$} & \multicolumn{2}{|l|}{$\mathrm{HDL}_{2 \mathrm{a}}$} & \multicolumn{2}{|l|}{$\mathrm{HDL}_{3 \mathrm{a}}$} & \multicolumn{2}{|l|}{$\mathrm{HDL}_{3 \mathrm{~b}}$} & \multicolumn{2}{|l|}{$\mathrm{HDL}_{3 \mathrm{c}}$} \\
\hline & cord blood & day 5 & cord blood & day 5 & cord blood & day 5 & cord blood & day 5 & cord blood & day 5 \\
\hline TERM (controls) & $25 \pm 9$ & $25 \pm 7$ & $17 \pm 3$ & $17 \pm 2$ & $16 \pm 2$ & $16 \pm 2$ & $15 \pm 3$ & $15 \pm 2$ & $27 \pm 8$ & $27 \pm 6$ \\
\hline ENT & $37 \pm 12^{a}$ & $27 \pm 7 *$ & $18 \pm 3$ & $16 \pm 2$ & $15 \pm 2$ & $15 \pm 2$ & $11 \pm 3$ & $15 \pm 3$ & $19 \pm 10^{\mathrm{a}}$ & $28 \pm 7 *$ \\
\hline TPN & $39 \pm 11^{\mathrm{a}}$ & $28 \pm 9 *$ & $18 \pm 3$ & $15 \pm 2$ & $14 \pm 2$ & $14 \pm 2$ & $11 \pm 3$ & $15 \pm 6$ & $18 \pm 8^{a}$ & $29 \pm 8^{*}$ \\
\hline
\end{tabular}

* Cord blood vs. day $5,{ }^{a}$ in comparison to the TERM group $(\mathrm{p}<0.001)$.

infants of the TPN group the phospholipid concentration became even higher than for the infants of the ENT group. The phospholipid levels increased significantly already on day 2 in all three groups (TERM $1.2 \pm 0.2$ vs. $1.89 \pm$ $0.28 \mathrm{mmol} / \mathrm{l}$; ENT $1.71 \pm 0.49$ vs. $2.36 \pm 0.36 \mathrm{mmol} / \mathrm{l}$; TPN $1.74 \pm 0.44$ vs. $2.3 \pm 0.49 \mathrm{mmol} / \mathrm{l})$. In the ENT group, the TC levels increased significantly $(1.1 \pm 0.04$ vs. $1.3 \pm 0.04 \mathrm{mmol} / \mathrm{l})$, and the HDL cholesterol level decreased significantly $(1.1 \pm 0.28$ vs. $0.8 \pm 0.26 \mathrm{mmol} / \mathrm{l})$ on day 2, whereas the other lipid concentrations and apo $\mathrm{AI}$ and AII levels were not significantly different from cord blood levels (data not shown).

\section{Gradient Gel Electrophoresis}

The values for the areas under the curve of the gradient gel electrophoresis scans are listed in table 3. The HDL subclass distribution as seen in table 3 did not change significantly in the TERM group. Cord blood samples of both groups of preterm infants (ENT and TPN) showed an increase in mass in the $\mathrm{HDL}_{2 \mathrm{~b}}$ region and less mass in the $\mathrm{HDL}_{3 \mathrm{c}}$ region. On day 5, the scans of both groups (ENT and TPN) showed a statistically significant shift of particles from the large less dense $\mathrm{HDL}_{2 b}$ region to the smaller more dense particles in the $\mathrm{HDL}_{3 \mathrm{c}}$ region. Therefore, on day 5 , there was no longer a difference in HDL 
subclass distribution between TERM group and both groups of preterm infants. Only in a minority of the TPN infants persistently low HDL cholesterol levels were observed, similar to the pattern observed in our previous study [10]. As the lipids levels, the areas under the curve did not correlate with the gestational age.

\section{Discussion}

The postnatal development of the HDL subclass distribution in parenterally nourished infants who are started on early enteral nutrition has previously not been studied. We were able to show that preterm infants with low-level enteral feedings during the first days of life in addition to their parenteral nutrition do not exhibit the abnormal HDL pattern previously reported in solely parenterally nourished infants, but show the same transformation of large HDL to small $\mathrm{HDL}_{3 \mathrm{c}}$ particles as completely enterally fed preterm infants [11]. The HDL distribution previously reported in infants not fed enterally resembles most closely the HDL distribution of LCAT-deficient patients [10]. Exclusively parenterally fed rats exhibit mucosal hypoplasia and hypofunction of the intestine within days, with changes in the protein metabolism. In particular, the urea cycle amino acid concentrations were altered in plasma and mucosa of solely parenterally fed pigs, suggesting that the arginine synthesis by an atrophied gut may have been limited. Gut atrophy resulted in significantly lower concentrations of all indispensable amino acids as compared with enterally fed pigs [15-18]. Feeding small amounts of enteral nutrition to parenterally nourished preterm infants may not only facilitate better enteral feeding tolerance, but also influence the metabolism of a parenteral lipid emulsion. This might be of particular interest in extremely preterm infants who frequently are nourished parenterally for weeks and in whom enteral feeding is often delayed for the fear of necrotizing enterocolitis. Starting enteral nutrition very early allows a more rapid increase in enteral feedings. Our group of TPN infants received a fairly large part of their nutrition enterally on day 5. Since feeding very-low-birth-weight infants enterally is a standard procedure in our unit, it was not feasible to randomize infants to a later start or to a restricted increase in enteral feedings.

The lack of postnatal changes in the HDL subclass distribution of healthy term infants despite increased TG levels is not readily explained, since an increase in TG is usually accompanied by an increase in small, dense $\mathrm{HDL}_{3}$. In particular the persistent lack of material in the
$\mathrm{HDL}_{3 \mathrm{a}}$ region is of interest. This region contains the main peak in adults and the least amount of material in cord blood [8, 9]. Cord blood lipoproteins consist predominantly of HDL, small amounts of low-density lipoprotein, and nearly no very low density lipoproteins and chylomicrons. Since there is an inverse relation between $\mathrm{HDL}_{2}$ and very low density lipoproteins, the postnatal increase of TG and the concomitant increase in very low density lipoproteins should lead to a decrease of $\mathrm{HDL}_{2}$ particles. Even though enteral nutrition led to increased TG, lowdensity and very low density lipoprotein, and chylomicron levels in all three groups, the HDL subclass distribution changed only in the preterm infants but not in term infants. Davis et al. [8] and Silliman et al. [19, 20] reported a shift in the HDL subclass distribution during late pregnancy with an increase of particles in the $\mathrm{HDL}_{2 b}$ region. Estrogen levels were associated strongly with the $\mathrm{HDL}_{2 \mathrm{~b}}$ mass. Estrogen has a half-life of a few days, and possibly the observed postnatal changes in our preterm infants were caused by decreasing estrogen levels.

Previous studies [9, 21-24] demonstrated that the HDL cholesterol levels are elevated in cord blood in preterm infants, but declined within the first 5 days of life to levels as seen in term infants. The HDL cholesterol values found in our study are comparable to those reported by Decsi et al. [25] in preterm infants during the first 10 days of life.

The apo AI levels increased postnatally in all three groups. The influence of the gestational age on the apo AI concentration is under debate. Parker et al. [23] described an influence of gestational age on apo AI, but found a positive correlation with increasing levels only between 21 and 32 weeks of gestation. The overall cord blood apo AI levels are approximately $60-70 \%$ of those of adults [26, 27]. The apo AI levels increase in plasma after a fatty meal. A postnatal increase of apo AI has been observed previously in healthy enterally fed term and preterm infants [8, 10, 26-29]. Apo AI as a cofactor of LCAT is essential for metabolizing intravenous lipid emulsion constituents, but the level of this enzyme is very low in parenterally fed preterm infants [10, 29, 30]. It is of importance that in contrast to our previous study on entirely parenterally fed preterm infants [10], the preterm infants in the present study who received parenteral nutrition along with a small amount of enteral nutrition for gut priming had postnatal apo AI levels comparable to those of term infants and displayed the same rise in apo AI as exclusively enterally fed preterm infants. The postnatal increase of apo AI happens predominantly in the $\mathrm{HDL}_{3 b+3 c}$ region [28]. Since significant amounts of apo AI 
are secreted by the intestine [13], the early enteral nutrition in the TPN group facilitated the previously not reported postnatal rise in apo $\mathrm{AI}$ in this group.

Parallel to the increase of apo AI, we also observed a rise of mass in the $\mathrm{HDL}_{3 \mathrm{~b}+3 \mathrm{c}}$ region which is likely to be caused by an increase in protein content and not in lipid particle levels, since the $\mathrm{HDL}_{3}$ cholesterol levels did not increase. Postnatally unchanged $\mathrm{HDL}_{3}$ cholesterol levels are in accordance with the findings of Decsi et al. [31].

Data on apo AII levels in infancy are sparse [27, 31, 32], but are similar to our values. There is also little information on plasma phospholipid concentrations in newborns. Dolphin et al. [33] reported slightly lower levels, but his method did not exclude lysolecithin. Jain and Diaz [34] did not find a correlation between gestational age and phospholipid levels in cord blood which is in contrast to our data, showing that preterm infants had significantly higher levels than the TERM group infants. Our cord blood data and the increased levels during parenteral lipid emulsion are in accordance with the findings reported by Haumont et al. [35, 36], as are the levels of phospholipids in the enterally fed preterm infants. The increased phospholipid levels in parenterally fed infants are mostly likely caused by the phospholipids of the lipid emulsion.

To conclude, early enteral feeding in parenterally nourished preterm infants may prevent intestinal atrophy and, therefore, lead to an increase in apo AI levels. Early enteral feeding may facilitate the same postnatal changes in HDL subclass distribution, including a shift from large to small HDL particles as in fully enterally fed preterm infants. These findings are opposite to previously reported changes observed in exclusively parenterally nourished infants. Therefore, early feeding not only facilitates better enteral nutrition, it also enhances parenteral nutrition tolerance. Whether improved nutrition during the $1 \mathrm{st}$ week of life has implications on the long-term outcome still needs to be proven.

\section{Acknowledgement}

The study was made possible by a grant from the Walter Schulz Stiftung.

\section{References}

1 Aynsley-Green A, Lucas A, Lawson GR, Bloom SR: Gut hormones and regulatory peptides in relation to enteral feeding, gastroenteritis, and necrotizing enterocolitis in infancy. $\mathrm{J}$ Pediatr 1990;117(suppl):24-32.

2 Lucas A, Bloom SR, Aynsley-Green A: Gut hormones and 'minimal enteral feeding'. Acta Paediatr 1986;75:719-723.

3 Berseth CL: Effect of early enteral feeding on maturation of the preterm infant's small intestine. J Pediatr 1992;120:947-953.

4 Berseth CL: Neonatal small intestinal motility: Motor response to feeding in term and preterm infants. J Pediatr 1990;117:777-782.

5 Bisset WM, Watt J, Rivers RPA, Milla PJ Postprandial motor response of small intestine to enteral feeds in preterm infants. Arch Dis Child 1989;64:1356-1361

6 Nichols AV, Blanche PJ, Gong EL: Gradient gel electrophoresis of human plasma high density lipoproteins; in Lewis L (ed): CRC Handbook of Electrophoresis. Boca Raton, CRC Press, 1983, pp 29-47.

7 Blanche PJ, Gong EL, Forte T, Nichols AV: Characterization of human HDL by gradient gel electrophoresis. Biochim Biophys Acta 1981;408:408-419.

8 Davis PA, Forte T, Nichols AV: Umbilical cord blood lipoproteins: Isolation and characterization of high density lipoproteins. Arteriosclerosis 1983;3:357-365.
9 Genzel-Boroviczény OM, Forte T, Austin MA: High density lipoprotein subclass distribution and human cord blood lipid levels. Pediatr Res 1986;20:487-491.

10 Forte TM, Genzel-Boroviczény OM, Austin MA, Kao LC, Scott C, Albers JJ, D'Harlingue AE: Effect of total parenteral nutrition with intravenous fat on lipids and high density lipoprotein heterogeneity in neonates. JPEN 1989; 13:490-500.

11 Genzel-Boroviczény OM, D’Harlingue AE, Kao LC, Scott C, Forte TM: High-density lipoprotein subclass distribution in premature infants before and after onset of enteral feedings. Pediatr Res 1988;23:543-547.

12 Beau P, Ferezou J, Hajri T, Serougne C, Matuchansky C, Lutton C: Metabolism of plasma cholesterol and lipoproteins after total resection of the small intestine in patients with parenteral nutrition: Effects of the amount of phospholipids infused. Gastroenterol Clin Biol 1992;16:769-776.

13 Bisgaier CL, Glickman RM: Intestinal synthesis, secretion and transport of lipoproteins. Annu Rev Physiol 1983;45:625-636.

14 Schumaker VN, Puppione DL: Sequential flotation ultracentrifugation. Methods Enzymol 1986; 128:155-170

15 Hughes CA, Dowling RH: Speed of onset of adaptive mucosal hypoplasia and hypofunction in the intestine of parenterally fed rats. Clin Sci (Colch) 1980;59:317-327.
16 Yoshida S, Tajiri T, Yahara T, Yoshizumi T, Tanaka K, Muraoka T, Yamasaki K, Shirouzu $\mathrm{K}$ : Administration of opiate receptor antagonist inhibits mucosal atrophy of the gut in fasting rats. J Surg Res 2000;93:177-181.

17 Bertolo RF, Chen CZ, Pencharz PB, Ball RO: Intestinal atrophy has a greater impact on nitrogen metabolism than liver by-pass in piglets fed identical diets via gastric, central venous or portal venous routes. J Nutr 1999;129:10451052.

18 Bertolo RF, Pencharz PB, Ball RO: Organ and plasma amino acid concentrations are profoundly different in piglets fed identical diets via gastric, central venous or portal venous routes. J Nutr 2000;130:1261-1266.

19 Silliman K, Shore V, Forte TM: Hypertriglyceridemia during late pregnancy is associated with the formation of small dense low-density lipoproteins and the presence of large buoyant high-density lipoproteins. Metabolism 1994; 43:1035-1041.

20 Silliman K, Tall AR, Kretchmer N, Forte TM: Unusual high-density lipoprotein subclass distribution during late pregnancy. Metabolism 1993;42:1592-1599.

21 Fosbrooke AS, Wharton BA: Plasma lipids in umbilical cord blood from infants of normal and low birth weight. Biol Neonate 1973;23: 330-338. 
22 Ginsburg BE, Zetterström R: Serum cholesterol concentrations in newborn infants with gestational ages of 28-42 weeks. Acta Paediatr Scand 1980;69:587-592.

23 Parker CR Jr, Fortunato SJ, Carr BR, Owen J, Hankins GD, Hauth JC: Apolipoprotein A-1 in umbilical cord blood of newborn infants: Relation to gestational age and high-density lipoprotein cholesterol. Pediatr Res 1988;23:348351.

24 Toth P, Klujber L, Baranyai Z, Molnar E: Serum lipid and lipoprotein-cholesterol values in cord blood and on the sixth postnatal day in newborns of varying maturity. Acta Paediatr Hung 1984;25:275-281.

25 Decsi T, Molnár D, Klujber L: Lipid levels in very low birthweight preterm infants. Acta Paediatr Scand 1990;79:577-580.

26 Lane DM, McConathy WJ: Changes in the serum lipids and apolipoproteins in the first four weeks of life. Pediatr Res 1986;20:332337.
27 Averna MR, Barbagallo CM, Di Paola G, Labisi M, Pinna G, Marino G, Dimita U, Notarbartolo A: Lipids, lipoproteins and apolipoproteins AI, AII, B, CII, CIII and E in newborns. Biol Neonate 1991;60:187-192.

28 van Biervliet JP, Rosseneu M, Bury J, Caster H, Stul MS, Lamote R: Apolipoprotein and lipid composition of plasma lipoproteins in neonates during the first month of life. Pediatr Res 1986;20:324-328.

29 Amr S, Chowdhry P, Hamosh P, Hamosh M: Low levels of apolipoprotein A1 are not contributors to the low lecithin-cholesterol acyl transferase activity in premature newborn infants. Pediatr Res 1988;24:191-193.

30 Spear ML, Amr S, Hamosh M, Pereira GR, Corcoran LG, Hamosh P: Lecithin:cholesterol acyltransferase (LCAT) activity during lipid infusion in premature infants. J Pediatr Gastroenterol Nutr 1991;13:72-76.

31 Decsi T, Fekete M, Szasz M, Burus I: Lipid and apolipoprotein levels and enteral nutrition in very low-birth-weight preterm infants. Acta Paediatr 1993;82:663-665.

32 Strobl W, Widhalm K, Kostner G, Pollak A: Serum apolipoproteins and lipoprotein (a) during the first week of life. Acta Paediatr Scand 1983;72:505-509.
33 Dolphin PJ, Breckenridge WC, Dolphin MA, Tan MH: The lipoproteins of human umbilical cord blood apolipoprotein and lipid levels. Atherosclerosis 1984;51:109-122.

34 Jain SK, Diaz JJ: Plasma lecithin-cholesterol acyltransferase activity and cholesterol and phospholipid levels in premature newborn infants. Biochim Biophys Acta 1991;1086:225229.

35 Haumont D, Deckelbaum RJ, Richelle M, Dahlan W, Coussaert E, Bihain B, Carpentier YA: Plasma lipid and plasma lipoprotein concentrations in low birth weight infants given parenteral nutrition with twenty or ten percent lipid emulsion. J Pediatr 1989; 115:787-794.

36 Haumont D, Richelle M, Deckelbaum RJ, Coussaert E, Carpentier YA: Effect of liposomal content of lipid emulsions on plasma lipid concentrations in low birth weight infants receiving parenteral nutrition. J Pediatr 1992; 121:759-763. 